\title{
DIFFERENTIAL THERMAL ANALYSIS OF NICKEL-BASE SUPERALLOYS
}

\author{
D.L. Sponseller \\ ERIM Transportation \& Energy Materials Laboratory \\ 4683 Freedom Drive \\ Ann Arbor, Michigan 48108
}

\begin{abstract}
$\underline{\text { Abstract }}$
Differential thermal analysis was performed on over 200 nickel-base superalloys that included model, experimental, developmental, and commercial alloys. About one-half of these alloys were studied during melting and solidification, and about three-fourths were studied using solid specimens. Large samples were employed to permit the use of internal thermocouples and to minimize both the effects of segregation and the changes in chemical composition resulting from the loss of strong oxide-forming components. The features of thermograms for solid specimens were identified by two calibration techniques: (1) Inserting thin bar specimens of four cast alloys into a gradient furnace so that all parts of the test specimen were heated at the same rate as in a DTA test to the temperature range of interest; water quenching preserved the entire range of microstructures for metallographic evaluation. (2) Heating (and cooling, when applicable) 35 disc specimens of various alloys to points of interest on the heating thermogram and especially on the cooling thermogram, at which point each specimen was water quenched and evaluated metallographically. The effects of alloying elements on liquidus temperature, carbide-formation temperature, and the extent of carbide dispersion in the cast structure, $\gamma^{\prime}$ solvus temperatures (for DT $\Lambda$ heating/cooling rates and for practical heat treatments and soaking treatments), incipient-melting temperature, and the width of the temperature "window" for solution-heat-treating of single-crystal alloys are presented. Some examples of problem solving by DTA related to cracking during casting caused by verylow-melting liquid and to microporosity related to the $\gamma+\gamma^{\prime}$ eutectic constituent are presented.
\end{abstract}

\section{Introduction}

Phase reactions play a crucial role in many aspects of the processing and service of high-strength nickel-base superalloys. Before 1968, however, the determination of the most important phase-reaction temperature, that at which the $\gamma^{\prime}$ strengthening precipitate dissolves, required the laborious heat-treating and metallography of many specimens, and begged for a simpler technique. The ability of differential thermal analysis (DTA) to simply and accurately measure the temperatures of phase reactions in materials was first discovered by LeChateliér in 1887, and perfected for metals by Roberts-Austen in $1899(1,2)$. Considering its great utility in the study of phase reactions, DTA has generally been underutilized, however, by the metallurgical community. Because the author had successfully used DTA to help identify elevated-temperature ductile-iron compositions that could be used to $815 \mathrm{C}(1500 \mathrm{~F})$ without re-austenitization,
DTA was investigated at the Climax Molybdenum ( $\triangle \mathrm{MAX}$ ) laboratory in 1968 as a means of directly measuring the $\gamma^{\prime}$ solvus temperature in nickel-base alloys $(3,4)$. It was found that DTA gives a clear and accurate indication of the $\gamma^{\prime}$ solvus temperature during both heating and cooling. Following this discovery, DTA was used in many other superalloy studies at the Climax laboratory. Also, DTA was performed on as many as five sets of samples received from each of the following companies seeking DTA-based data and interpretation in their R\&D and problem-solving.

Allied Signal (Garrett Engine)
Allison Gas Turbine
Cannon-Muskegon
Carpenter Technology
Cytemp
General Electric
Haynes International
Howmet

Pratt \& Whitney
Precision Castparts
Rolls Rnyce
Ross \& Catherall
Sorcery Metals
Special Metals
Westinghouse

Results obtained on more than 200 model, experimental, developmental, and commercial alloys to date have demonstrated the power of DTA to provide invaluable guidance in the alloy and process development, production, and characterization of superalloys $(5,6)$.

The purpose of this paper is to document the main findings from the above studies. It is hoped that the sharing of this information with others in the superalloy community may help to further advance the state of the art in the metallurgy of gas-turbine alloys for the transportation, energy, industrial, and military sectors.

\section{$\underline{\text { Solidification Studies }}$}

\section{Experimental Procedure}

Test specimens for studies of melting and solidification weighed 9 grams, about 100 times heavier than the 50 to $150-\mathrm{mg}$ samples used in most commercial DTA units. This avoided the variation of results associated with segregation, especially for samples taken from ingots and investment castings, and minimized changes in chemical composition associated with oxidation of strong oxide formers such as aluminum, titanium, and hafnium that would show up especially on resolidification. An additional advantage is that the large specimen, shown in Figure 1, permitted the use of the pictured small immersion thermocouple (W-W/Re type) to avoid errors in sensing the specimen temperature. The test specimen, and two similarly shaped pure-molybdenum specimens (one containing the reference thermocouple and the other containing the furnace-control 

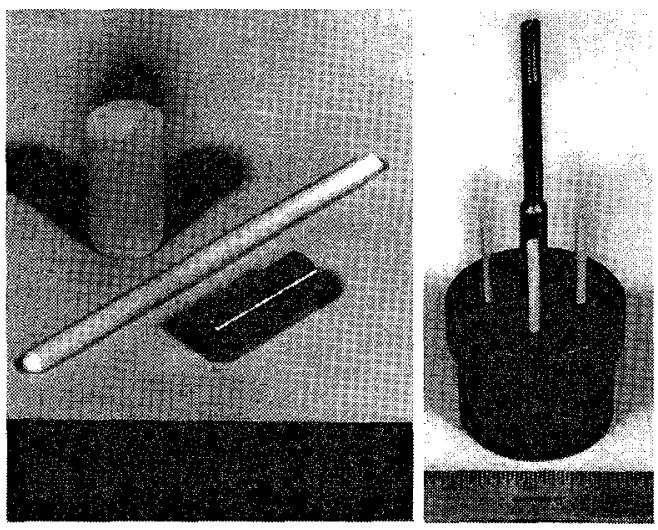

Figure 1. DTA cell for melting/solidification studies, showing: (left) 9-g machined specimen with drilled axial thermocouple hole, high-purity tecrystallized alumina thermocouple tube and crucible and (right) assembly ready for thermocouple insertion and test, showing pure molybdenum block with thick lid that keeps the thermocouple tube centered in the sample when molten, and threaded hanger rod.

thermocouple) all were similarly situated in high-purity recrystallized alumina crucibles contained within a pure molybdenum block, with a thick, close-fitting lid, that was suspended from the top of a resistance-heated vacuum furnace. A 4-wire thermocouple was used in the specimens for all but some of the early runs, so that this thcrmocouple could both oppose the reference thermocouple and drive the $\mathrm{X}$ axis, eliminating the need for any temperature corrections in "reading" the thermograms. In each DTA experiment, the assembly was first heated and then cooled through the melting range at $10 \mathrm{C} / \mathrm{min}$, followed by a similar run at $20 \mathrm{C} / \mathrm{min}$. Plots of $\Delta \mathrm{T}$ vs specinen temperature were obtained with an $\mathrm{X}-\mathrm{Y}$ recorder. The system was straight-forward to use, and gave consistent and reliable results. Tested specimens were normally examined metallographically. Approximately 100 different superalloys were so tested; not all of these alloys, however, are represented in this paper.

\section{Alloying Effects}

Model Alloys. A series of eight model alloys was melted, to delineate the effects of key alloying elements on the melting/solidification behavior of nickel-base alloys. To a base composition of $\mathrm{Ni}-15 \mathrm{Cr}-10 \mathrm{Co}-5 \mathrm{Mo}-3 \mathrm{Al}$ were added 0.16 and $0.32 \%$ $\mathrm{C}$, an additional $3 \% \mathrm{Al}, 3$ and $6 \% \mathrm{Ti}$, and $6 \% \mathrm{Ta}$, in various combinations. Thermograms for the base alloy and three modifications, along with final microstructures, are shown in Figure 2a. The base alloy shows the expected strong endothermic effect during melting and exothermic effect during solidification at $10 \mathrm{C} / \mathrm{min}$, with no unusual features except for some (up to $23 \mathrm{C}$ [42 F]) undercooling and recalescence at the start of solidification. All three thermograms for the model alloys in Figure 2a show inflections associated with the melting/solidification of the carbide eutectic. Of special interest is the position of this eutectic reaction with respect to the type of carbide involved. The reaction comes very late in the solidification process for the alloy containing no titanium, but much earlier for the titanium-containing alloys. Tantalum was found to have a similar effect to that of titanium. This simply reflects the fact that these two alloying elements are much stronger carbide formers than is chromium. Correspondingly, the chromium carbide is more clearly segregated at dendritic interstices than are the titanium or tantalum carbides. (Though not presented in this paper, a thermogram for IN-738 containing
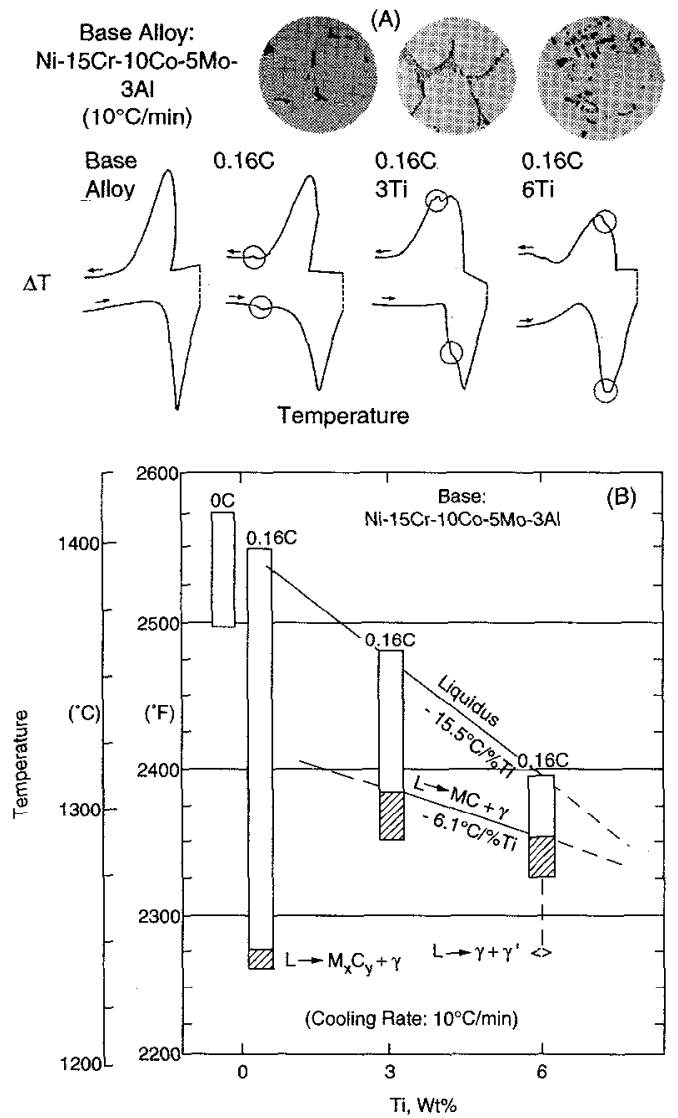

Figure 2. Results of melting/sol idification studies of four model alloys of indicated compositions. (a) Thermograms obtained during melting and solidification, showing undercooling and recalescence of the two alloys without titanium and showing the carbide eutectic reactions (encircled) in the carbon-containing alloys. Microstructures of the three alloys with carbon, after solidification during the second run $(20 \mathrm{C} / \mathrm{min})$, are shown. (b) Solidification ranges obtained from the thermograms of (a), showing the effect of the carbon addition and then of titanium additions on the liquidus temperature. Note the very low temperature of the carbide eutectic reaction in the absence of titanium, and the reaction's progressive approach toward the liquidus temperature with increasing titanium content.

$0.17 \% \mathrm{C}$ and $0.10 \% \mathrm{Zr}$, in which the carbide eutectic inflection occurs at a much earlier point during solidification--midway up the rising part of the exotherm in the solidification thermogram--has carbides that are distributed much more widely throughout the structure than in the model alloy containing no titanium, the carbide eutectic in IN-738 occupying roughly one-half of the specimen volume. This shows that the thermogram can serve as an indicator of whether carbides are highly segregated or well dispersed in the cast structure.) The model alloy containing $0.16 \% \mathrm{C}, 3 \% \mathrm{Al}, 3 \% \mathrm{Ti}$, and $6 \%$ Ta formed some carbides $75 \mathrm{C}(135 \mathrm{~F})$ above the start of metallic dendrite formation.

The effect of the stability of the carbide on the temperature of its eutectic reaction may be seen more quantitatively in Figure $2 b$. The solidification range for the alloy containing carbon but no strong carbide formers is approximately $155 \mathrm{C}(275 \mathrm{~F})$, but the ranges for the titanium-containing alloys are less than one-half this amount. Figure $2 \mathrm{~b}$ also shows that the liquidus temperatures are depressed, first mildly by the carbon addition, then more strongly by the additions of 3 and $6 \% \mathrm{Ti}$. The relationship between chemical composition and liquidus temperature is seen more clearly in Figure 3 , a plot of liquidus temperature vs hardener content. The slopes of 
the line segments connecting the data points representing the individual alloys are labeled with the specific melting-pointdepressing effect $(\Delta T$ per $1 \mathrm{wt} p c t)$ of the one element that varies between the two alloys. Titanium exhibits the strongest specific effect, with an average value of $14.2 \mathrm{C}(25.5 \mathrm{~F}) / \mathrm{wt}$ pct. That of aluminum is somewhat weaker, $12.2 \mathrm{C}(22 \mathrm{~F}) / 1 \mathrm{wt}$ pct, while that of tantalum is the weakest of the three hardeners, with an average value of $4.8 \mathrm{C}(8.5 \mathrm{~F}) / 1$ wt pct.

Commercial Alloys. Thermograms taken during melting and solidification of the commercial alloy IN-100 and its experimental niobium-free modification are presented in Figure 4a. The main thermal effects during melting and solidification are shifted to the right by removal of niobium, with the exact changes being denoted more clearly in the bar graph of Figure $4 \mathrm{~b}$. Removal of niobium also brings out a carbide eutectic reaction at the end of solidification. At the left ends of the thermograms are endotherms revealed during heating and exotherms revealed during cooling caused by the dissolution and precipitation, respectively, of $\gamma^{\prime}$. Removing niobium from IN-100 causes a wide flat spot in the thermogram reflecting the fact that the loss of niobium moves the melting/solidification and $\gamma^{\prime}$ dissolution/precipitation reactions in opposite directions.

A bar graph showing the melting ranges of six well-known commercial superalloys during heating at $10 \mathrm{C} / \mathrm{min}$ is presented in Figure 5. The alloys are arranged in order of increasing $\mathrm{Al}+\mathrm{Ti}$ content, since these elements are the dominant metallic melting-point depressants, as shown above. The highest-melting of these alloys is the iron-base superalloy A-286, its high liquidus temperature $(1410 \mathrm{C}[2570 \mathrm{~F}])$ resulting not just from its low $(2.2 \%) \mathrm{Al}+\mathrm{Ti}$ content but from its high (54\%) iron content. Liquidus temperatures drop more-or-less regularly in going to the progressively higher $\mathrm{Al}+$ Ti contents of Waspaloy, Alloy 713LC, IN-738, and René 80, which has a liquidus temperature of just $1323 \mathrm{C}(2413 \mathrm{~F})$. Owing to its high cobalt content, the melting range for $\mathrm{IN}-100$ lies above the trend line for the other alloys. Liquidus temperatures agree rather closely with those for the model alloys (dashed line) of Figure 3.

Table I presents the liquidus temperatures of two heats of IN-738, one having the original levels of carbon and zirconium, and the other having reduced levels of these elements. Whether measured during tests at $10 \mathrm{C} / \mathrm{min}$ or $20 \mathrm{C} / \mathrm{min}$, and during heating or cooling, all increases lie between 7 and $9 \mathrm{C}(13$ and $16 \mathrm{~F})$, the mean increase being $8 \mathrm{C}(15 \mathrm{~F})$. This consistent assessment of the change in liquidus temperature resulting from a minor change in chemical

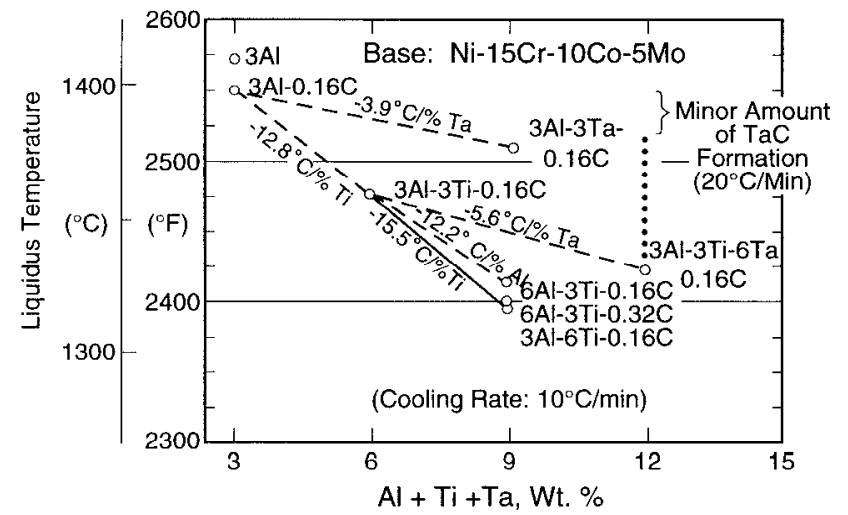

Figure 3. Graphical summary of the effects of carbon, aluminum, titanium, and tantalum on liquidus temperature of model alloys. Note indication of carbide formation well above the liquidus in the $6 \%$ Ta alloy when cooled at $20 \mathrm{C} / \mathrm{min}$.
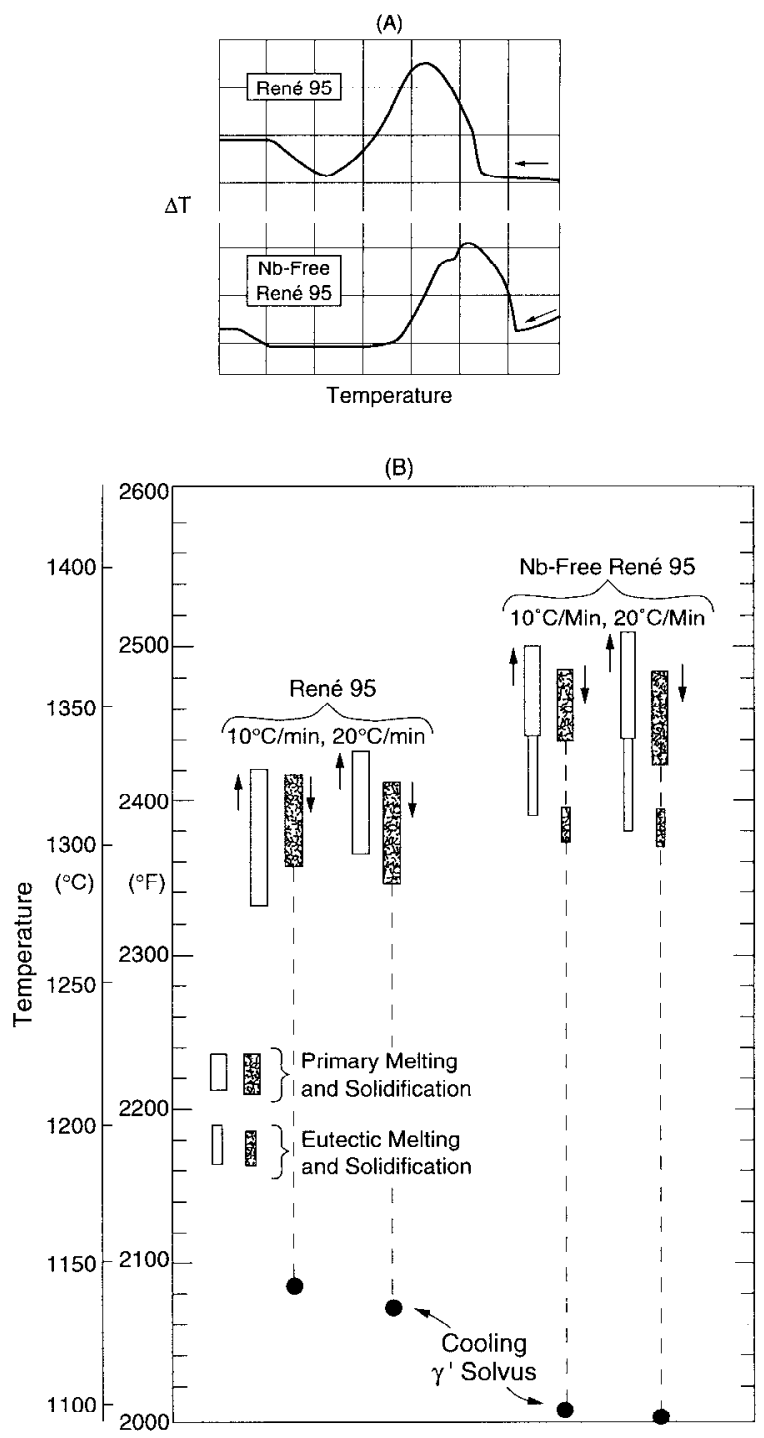

Figure 4. Effect of removal of niobium from René 95 on melting and solidification. (a) Comparison of solidification thermograms obtained at $10 \mathrm{C} / \mathrm{min}$. (b) Melting/solidification ranges, showing increase in liquidus temperature and increase in temperature interval between the solidification range and the start of $\gamma^{\prime}$ precipitation during cooling, resulting from removal of niobium.

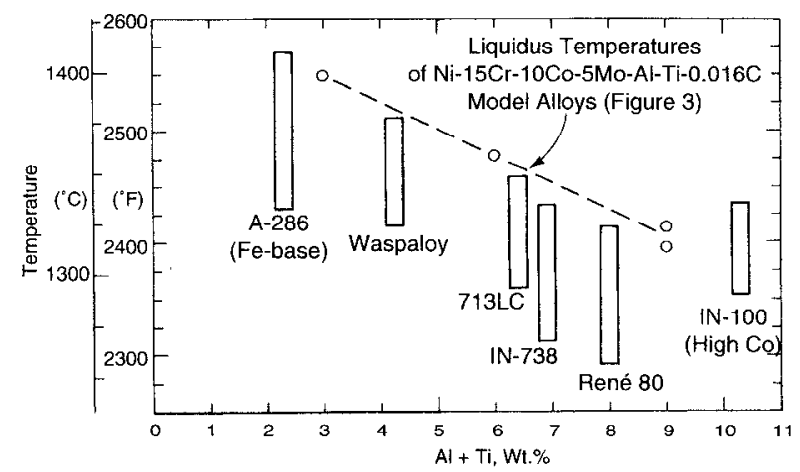

Figure 5. Variation of melting ranges of some commercial alloys with $\mathrm{Al}+\mathrm{Ti}$ content during heating at $10 \mathrm{C} / \mathrm{min}$. Liquidus temperatures agree closely with those for the Ni-0.16C-15Cr-10Co-5Mo-Al-Ti model alloys of Figure 3. 
Table I. Effects of Small Changes in Composition on Liquidus Temperature of $\mathbf{N}-738$

\begin{tabular}{|c|c|c|c|c|c|}
\hline \multirow[b]{2}{*}{$\begin{array}{l}\text { Rate, } \\
\text { C/Min }\end{array}$} & \multirow[b]{2}{*}{ Mode } & \multicolumn{3}{|c|}{ Liquidus Temperature, $C(F)$} & \multirow{4}{*}{$\begin{array}{l}\text { Mean Difference, } \\
+8 \mathrm{C}(+15 \mathrm{~F})\end{array}$} \\
\hline & & $\begin{array}{c}\text { Standard } \\
\text { IN }-738 \\
(0.17 \mathrm{C}-0.10 \mathrm{Z})\end{array}$ & $\begin{array}{c}\text { Low } \mathrm{C}, \mathrm{Zr} \\
\text { IN-738 } \\
(0.11 \mathrm{C}-0.04 \mathrm{Zr})\end{array}$ & $\begin{array}{c}\text { Difference, } \\
\mathrm{C}(\mathrm{F})\end{array}$ & \\
\hline 10 & $\begin{array}{l}\text { Heating } \\
\text { Cooling }\end{array}$ & $\begin{array}{l}1325(2417) \\
1324(2415)\end{array}$ & $\begin{array}{l}1334(2433) \\
1331(2428)\end{array}$ & $\begin{array}{l}+9(+16) \\
+7(+13)\end{array}$ & \\
\hline 20 & $\begin{array}{l}\text { Heating } \\
\text { Cooling }\end{array}$ & $\begin{array}{l}1330(2425) \\
1322(2412)\end{array}$ & $\begin{array}{l}1339(2442) \\
1330(2427)\end{array}$ & $\begin{array}{l}+9(+17) \\
+8(+15)\end{array}$ & \\
\hline
\end{tabular}

Table II. Critical Temperatures for Six Commercial Heats of René 80 During Solidification at $10 \mathrm{C} / \mathrm{Min}$

\begin{tabular}{|c|c|c|c|c|c|c|c|c|}
\hline & \multicolumn{7}{|c|}{ Temperature. $\mathrm{C}$} & \multirow{2}{*}{$\begin{array}{c}\text { Mean } \\
\text { Deviation, C (F) }\end{array}$} \\
\hline & $\begin{array}{c}\text { Heat } \\
\text { A }\end{array}$ & $\begin{array}{c}\text { Heat } \\
\text { B }\end{array}$ & $\begin{array}{c}\text { Heat } \\
\text { C }\end{array}$ & $\begin{array}{c}\text { Heat } \\
\text { D }\end{array}$ & $\begin{array}{l}\text { Heat } \\
\text { E }\end{array}$ & $\begin{array}{l}\text { Heat } \\
\text { F }\end{array}$ & Mean & \\
\hline Liquidus & 1317 & 1317 & 1318 & 1323 & 1321 & 1323 & 1321 & $3(5)$ \\
\hline $\begin{array}{l}\text { Start of } \\
\text { MC } \\
\text { Formation }\end{array}$ & 1297 & 1299 & 1299 & 1299 & 1299 & 1301 & 1299 & $1(2)$ \\
\hline Solidus & 1273 & 1277 & 1277 & 1281 & 1280 & 1283 & 1278 & $3(5)$ \\
\hline $\begin{array}{l}\text { Start of } \\
\gamma+\gamma^{\prime} \\
\text { Eutectic } \\
\text { Formation }\end{array}$ & -- & 1207 & 1206 & 1207 & 1206 & - & 1206 & $2(3)$ \\
\hline$\gamma^{\prime}$ Solvus & 1149 & 1157 & 1153 & 1160 & 1160 & 1154 & 1156 & $3(6)$ \\
\hline
\end{tabular}

composition, so as to provide guidance in setting pouring temperatures and possibly controlling other operations, illustrates the value of DTA in process control of superalloy production.

A more complete characterization of the solidification process is presented in Table II for six heats of René 80 remelt ingot. Reported are (1) the liquidus temperature, (2) the start of the MC + $\gamma$ eutectic reaction, (3) the solidus temperature, (4) the start of the $\gamma+\gamma^{\prime}$ eutectic reaction, and (5) the $\gamma^{\prime}$ solvus temperature during cooling, marking the start of $\gamma^{\prime}$ precipitation, all measured during cooling at $10 \mathrm{C} / \mathrm{min}$. The mean deviations in these temperatures are 1 to $3 \mathrm{C}(2$ to $6 \mathrm{~F})$. Since these differences reflect the heat-to-heat differences in chemical composition of the René 80 , as well as any errors in the DTA measurements, it is obvious from the small mean variations in the critical temperatures of the five reported phenomena that the DTA measurements are quite precise.

\section{Studies of Solid Specimens}

\section{Experimental Procedure}

Measurements of $\gamma^{\prime}$ solvus temperature, incipient-melting point, and several other effects wete made with a different type of specimen and test instrument than in the preceding section, Figure 6 . Cylindrical specimens weighing $4 \mathrm{~g}$ and with an axial thermocouple hole drilled to midlength were tested to a maximum temperature just above the incipient-melting point. This afforded greater precision than with the small specimens of commercial systems described above because of (1) the ability to place the thermocouple bead within and in direct contact with the specimen and (2) the higher magnification of the differential temperature that is made possible by avoiding the need to accommodate the large thermal effects encountered during full melting and solidification. The DTA

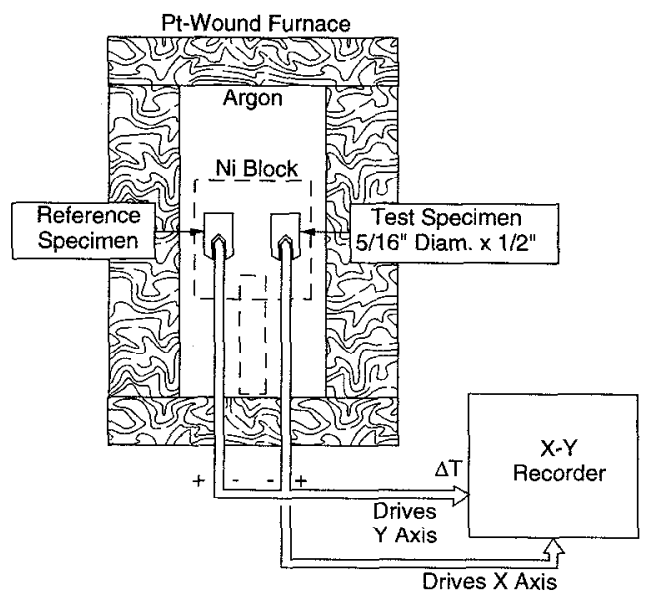

Figure 6. Physical arrangement for DTA tests of solid specimens.

specimen containing a 4-wire thermocouple, and a high-purity alumina reference specimen, both positioned in a cylindrical nickel block parallel to its axis and 180 degrees apart, were heated in a platinum-wound furnace at a constant rate (usually either 2 or $10 \mathrm{C} / \mathrm{min}$ ) to a certain maximum temperature. The peak temperature was higher than the $\gamma^{\prime}$ solvus temperature, of course, and generally was about $40 \mathrm{C}(70 \mathrm{~F})$ above the incipient-melting temperature for the $10 \mathrm{C} / \mathrm{min}$ heating rate, and was somewhat lower for the $2 \mathrm{C} / \mathrm{min}$ rate. No sagging of the specimen nor bleeding of eutectic liquids occurred unless the specimen had been heated a greater amount beyond the incipient-melting temperature. The specimen was normally cooled at a natural rate (with power off) of approximately $25 \mathrm{C} / \mathrm{min}$ through the $\gamma^{\prime}$ solvus temperature range, so as to achieve a very "clean" cooling curve, free of any slight thermal disturbances that can occur with the low power inputs of the cooling mode. In all, more than 150 different model, experimental, developmental, and commercial superalloys, often with multiple runs on each, have been so-tested to date.

\section{Interpretation of Thermograms}

The features of thermograms were identified in two ways: (1) by gradient-furnace experiments and (2) by quenching experiments, as illustrated in Figure 7. In the former method, a thin bar specimen, $64 \mathrm{~mm}$ (2.5 inches) in length and containing thermocouples embedded near each end, was manually advanced along the horizontal hearth in the slot-like chamber of a SATEC gradient furnace at a rate that achieved a heating rate of $10 \mathrm{C} / \mathrm{min}$. As soon as the temperature range within the specimen had encompassed all the critical temperatures of interest, the specimen was quenched vigorously in water. This procedure achieved the same microstructure at any point along the length of the specimen as if that point were contained in a normal DTA specimen being heated at $10 \mathrm{C} / \mathrm{min}$, and "froze" that microstructure for subsequent metallographic identification. Four cast alloys (IN-100, B-1900, B-1900 + Hf [MM-007], and Mar-M246 + Hf [MM-006]) were studied by this method. Obviously, a gradient specimen could not readily be physically arranged to approach the temperature span of critical temperatures from above the liquidus temperature, and thus the cooling portion of thermograms was "calibrated" by a series of quenching experiments. (A smaller number of points on the heating thermograms also were so-checked.) In each test, a thin disc was removed from the top of a normal specimen and, with a thin wire "handle" spot-welded to it, was placed in its original position on top 
of the shortened and thermocoupled DTA specimen. Covered by an insulating lid atop the nickel block, the test disc was taken through the DTA run to the point of interest. The furnace was quickly opened (a possibility facilitated by the design of the Harrop furnace), and the specimen was immediately (transfer time approximately $1 / 2$ second) quenched in water. Such quenching was done from the points denoted by the heavy dots on the thermogram of alloy Mar$\mathrm{M} 246$ + Hf (MM-006), as shown in Figure 7, and on some specimens of other alloys, for a total of 35 specimens. The quenched discs were subsequently studied by conventional, and in some cases SEM, metallography.

Based on the results of the above "calibration" studies on solid specimens, (annotated) thermograms for Mar-M246 + Hf, with the various critical temperatures and other features labeled, are presented in Figure 8. Most striking, of course, are the large endotherm during heating and exotherm during cooling caused by the dissolution and precipitation, respectively, of $\gamma^{\prime}$. In this paper, the peaks in these thermal perturbations are called the "maximum thermal effect" and

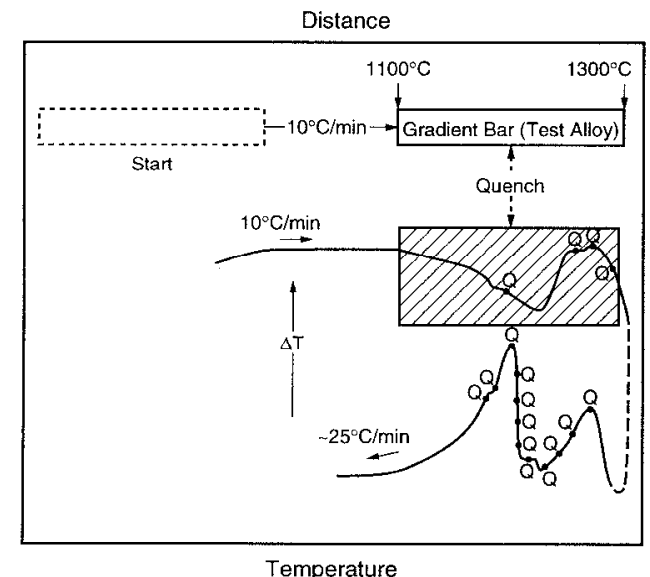

Figure 7. Method of obtaining metallographic samples for calibration of thermograms by means of gradient bars and selected quenched samples for heating thermograms (top and middle) and quenched samples for cooling thermograms (bottom).

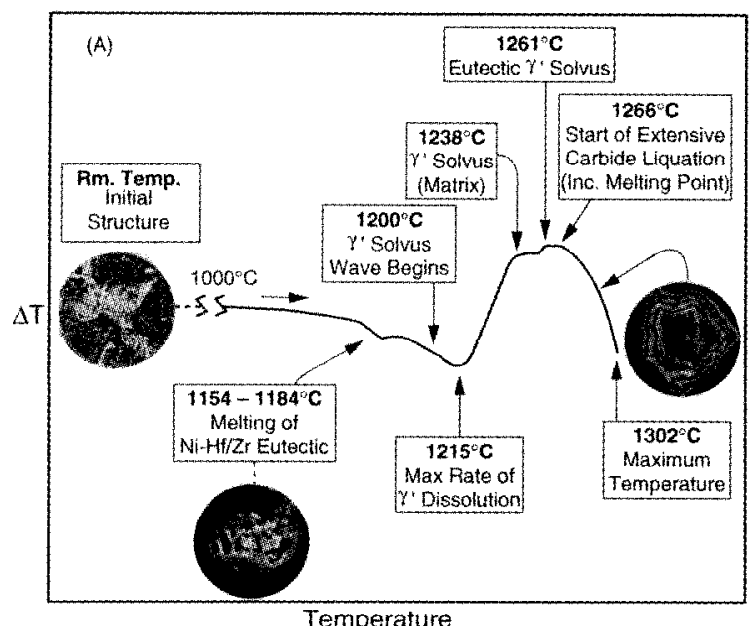

Figure 8A. Heating thermogram for Mar-M246 + Hf (MM-006), with critical temperatures and other key features labeled. Micrographs (SEM) at bottom and right show quenched liquid at $\mathrm{Hf} / \mathrm{Zr}$-enriched zone and at partially liquated carbide particle, respectively. Heating rate: $10 \mathrm{C} / \mathrm{min}$. correspond to the temperature at which there is the maximum timerate-of-change in the volume of $\gamma^{\prime}$ precipitate. The location of this peak reflects the combined effects of (1) the shape of the $\gamma^{\prime}$ solvus curve in the quasi phase diagram of temperature versus combined hardener content, (2) the degree of chemical segregation or "coring," especially in cast structures, and (3) heating or cooling rates and diffusion effects. In cast structures, the maximum thermal effect corresponds rather closely to the $\gamma^{\prime}$ solvus temperature at the centers of dendrite arms, these locations being leanest in hardener content. (Actually, the centers of dendrite arms reach their "solvus" during heating somewhat before the maximum thermal effect occurs, as indicated in Figure 8a.) During heating, the "front" marking total dissolution of matrix $\gamma^{\prime}$ precipitate advances in a wave that eventually has consumed each entire dendrite arm by the time the specimen reaches the $\gamma^{\prime}$ solvus temperature. During cooling, Figure $8 \mathrm{~b}$, the reverse process occurs. The $\gamma^{\prime}$ solvus temperatures during heating and cooling, then, are represented by the corners at the right ends of these large thermal effects, where the curve joins the baseline. The $\gamma^{\prime}$ solvus temperature during cooling is always lower than that during heating, due to diffusion effects--the equilibrium solvus temperature value lying somewhere between the heating and cooling values.

Heating thermograms for specimens containing large amounts of the $\gamma+\gamma^{\prime}$ eutectic constituent have a small inflection to the right of the main endotherm, caused by the dissolution of the coarser $\gamma^{\prime}$ particles that are characteristic of this constituent. The right end of this perturbation in the curve denotes the eutectic $\gamma^{\prime}$ solvus, Figure 8 a. Micrographs of such zones in disc samples quenched from temperatures just below and just above this small inflection during heating are shown in Figure 9, upper. Following the specimen's temperature excursion above the incipient-melting point, during which time the zones containing the former $\gamma+\gamma^{\prime}$ eutectic had remelted, disc specimens were quenched from just above and just below the corresponding inflection on the cooling curve. The hotter specimen exhibits pockets of quenched liquid (fine structure), while the cooler specimen contains the familiar $\gamma+\gamma^{\prime}$ eutectic nodules (separated by a small amount of very low-melting liquid), thus showing that the inflection represents solidification of this eutectic, having an appearance much like in the original casting.

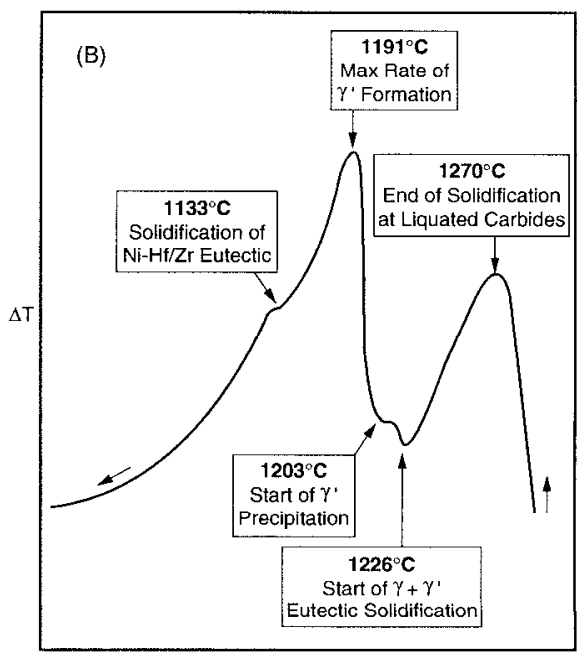

Temperature

Figure 8B. Same as Figure $8 \mathrm{~A}$, but during natural cooling after DTA specimen had been heated about $40 \mathrm{C}(70 \mathrm{~F})$ above the incipient-melting point. 
One of the most useful features of the present type of DTA test performed on solid specimens is its very sensitive detection of the incipient-melting point, or very beginning of the main melting process (ignoring the melting of the trace quantities of very low melting patches). The incipient-melting point is denoted by the corner at the right end of the heating thermogram where the curve breaks sharply downward. Because the thermocouple makes direct contact with the specimen, and because the differential temperature is highly expanded, as described previously, the incipient-melting point can be measured precisely, thus providing reliable guidance in heat-treating and other considerations. Physically, the incipientmelting point for typical superalloys containing carbon is the temperature at which carbides begin to liquate, i.e., to undergo the carbide eutectic solidification reaction in reverse. Such partial liquation of a carbide particle is seen in the SEM micrograph at the right-hand side of Figure $8 \mathrm{a}$. Though "calibration" experiments have not been done on carbon-free superalloys, the incipient-melting point in such alloys presumably corresponds to the melting of any undigested $\gamma+\gamma^{\prime}$ eutectic, or to the melting of the segregated zones of lowest melting point at dendrite interstices.

The final features of interest sometimes seen in thermograms of solid specimens are small inflections representing the melting and solidification at very low temperatures $(\approx 1150 \mathrm{C}[2100 \mathrm{~F}])$ of the tiny pockets of eutectic described above, containing such elements as zirconium, hafnium, boron, and phosphonus, combined with nickel. Zhu et al. have observed small pockets of such liquid even

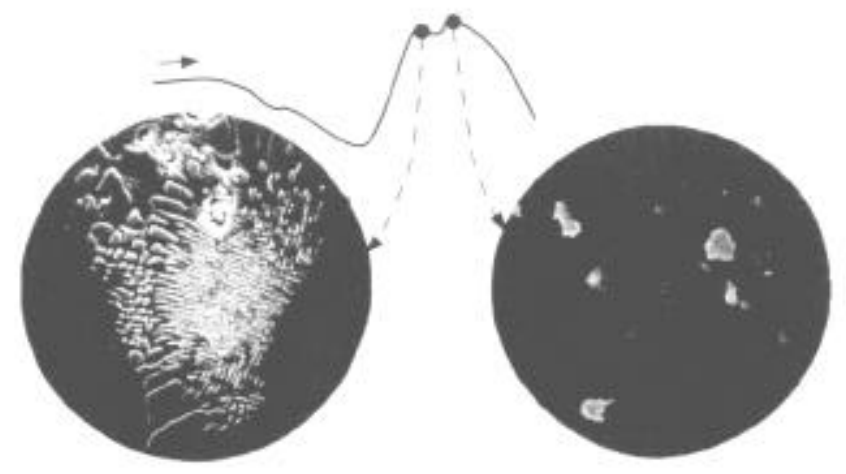

W.Q. From $1243^{\circ} \mathrm{C}$

W.Q. From $1266^{\circ} \mathrm{C}$

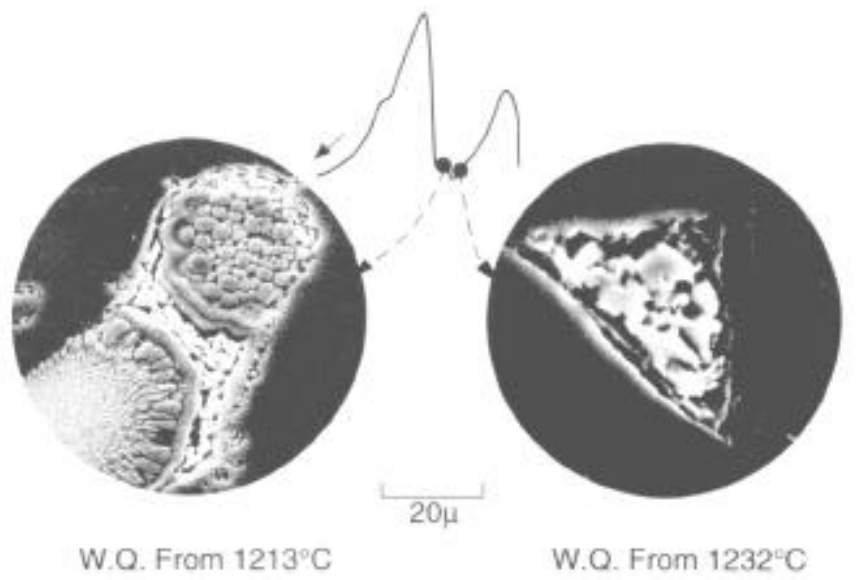

Figure 9. Scanning elecuon micrographs of Mar-M246 - Hf (MM-006) samples quenched from temperatures bracketing the thermogram features that denote the solvus semperature for eutectic $\gamma^{\prime}$ during beating (top) and the temperature for solidification of the $\gamma+\gamma^{\prime}$ eutectic during cooling (bottom). Note that only carbides remain above the eutectic $\gamma^{\prime}$ solvus. at $1100 \mathrm{C}(2010 \mathrm{~F})$ in slowly solidified nickel-base superalloys (7). These are located at interdendritic interstices and grain boundaries, between or adjacent to the $\gamma+\gamma^{\prime}$ eutectic nodules, when present, as seen in Figure 9. lower.

Knowledge of $\gamma^{\prime}$ solvus temperatures is often important in the control of solution-heat-treatment temperatures prior to precipitation hardening, and in the control of soaking temperatures for hot working. Thus it is important to know the relationship between $\gamma$ solvus temperature measured conveniently by DTA and the practical $\gamma^{\prime}$ solvus temperature for a heat treatment of some fixed duration at a constant temperature. Research at the AMAX laboratory and that of Maurer et al, has shown that the $\gamma^{\prime}$ solvus temperature measured by DTA drops moderately as heating rate decreases (8). In the present study, DTA results obtained at two heating rates for cast AF2-1DA and two of its modifications were compared with results for specimens heat treated two hours at six temperatures spaced $5.5 \mathrm{C}(10 \mathrm{~F})$ apart, and examined metallographically to determine the "practical" solvus temperature. The results, presented in Figure 10, show that the $\gamma^{\prime}$ solvus temperatures measured at $10 \mathrm{C}$ min lie above the "practical" solvus temperatures determined metallographically, the average temperature difference being about $15 \mathrm{C}(27 \mathrm{~F})$. Results for DTA specimens heated at $2 \mathrm{C} / \mathrm{min}$, however, agree closely with the metallographic study. This indicates that DTA tests should be made at lower heating rates than the commonly used $10 \mathrm{C} / \mathrm{min}$ rate when seeking guidance for practical heat treatments. Alternatively, subtracting a correction factor of about $15 \mathrm{C}(27 \mathrm{~F})$ for as-cast alloys (and presumably somewhat less for specimens with fine $\gamma^{\prime}$ particles that dissolve more readily) from the $\gamma^{\prime}$ solvus temperature determined by DTA at $10 \mathrm{C} / \mathrm{min}$ would most likely provide sufficient accuracy for control of heat-treating or soaking temperatures.

\section{$\gamma^{\prime}$ Solvus Temperatures}

Model alloys. The ability of DTA to accurately detect the $\gamma^{\prime}$ solvus temperature during heating and cooling was discovered during tests on a series of 16 model alloys (four molybdenum levels at each of four hardener levels) at the Climax Molybdenum (AMAX) laboratory in April 1968 by Loomis, Freeman, and Sponseller (4). The series of wrought alloys with controlled additions of molybdenum to a $\mathrm{Ni}-\mathrm{Cr}$ base ( $\mathrm{Ni} / \mathrm{Cr}$ ratio $=4,6$ on a weight basis) at four aluminum levels (one with titanium, not presented here) show progressive raising of the $\gamma^{\prime}$ solvus temperature by molybdenum as it dissolves in, and increases the quantity of, $\gamma^{\prime}$. Figure 11. The molybdenum

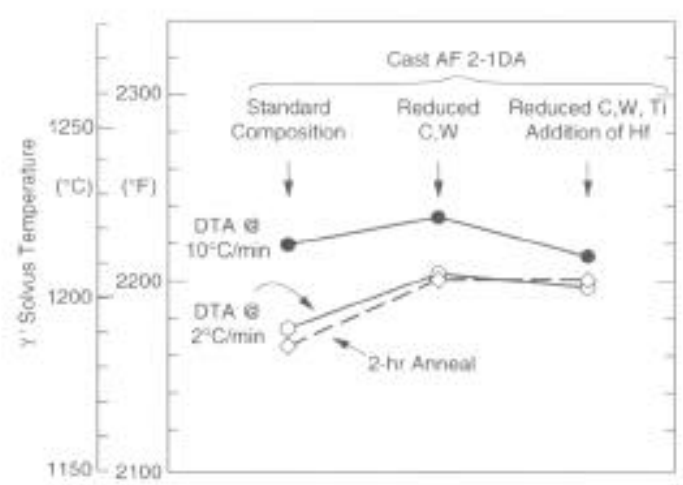

Figure 10, Comparisoa of $\gamma^{\prime}$ solvus temperatures determined by DTA during heating at $2 \mathrm{C} / \mathrm{m}$ in and $10 \mathrm{C} / \mathrm{min}$ with those obtained metallographically from specimens held two hours at temperatures spaced $5.5 \mathrm{C}$ (10 F) apart, for cast AF 2-IDA and two of its modifications. The slower hesting rate is seen to provide "practical" solvus temperatures. 


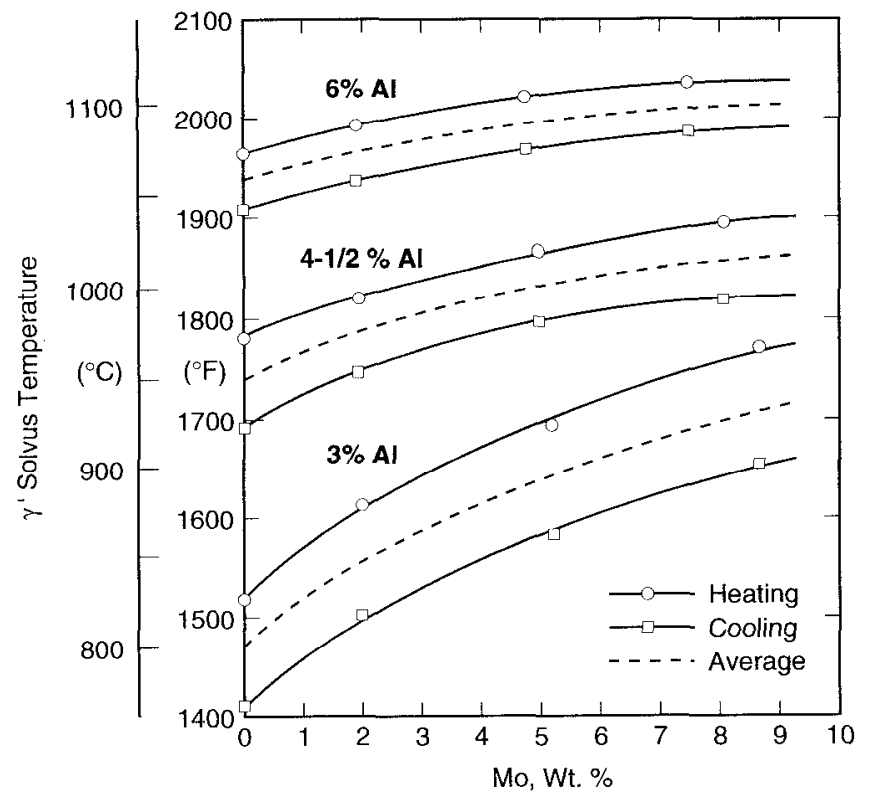

Figure 11. Effect of molyblenum on $\gamma^{\prime}$ sulvus temperature, as determined by DTA during heating and cooling at $10 \mathrm{C} / \mathrm{min}$ of model Ni-Cr-Al-Mo alloys having three levels of aluminum content (Ref. 4).

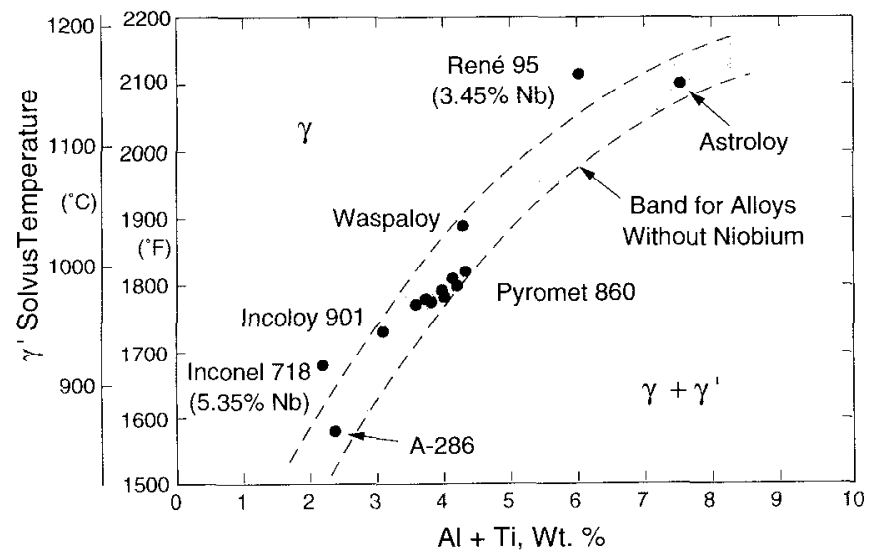

Figure 12. Variation of $\gamma^{\prime}$ solvus temperatures of seven wrought alloys with Al + Ti content. Niobium raises the data points for Inconel 718 and René 95 above the band for the niobium-free alloys. Values were obtained by DTA during heating at $10 \mathrm{C} / \mathrm{min}$.

effect decreases as solvus temperature increases, suggesting a kind of exhaustion or compression effect, as the melting range is approached. The equilibrium $\gamma^{\prime}$ solvus temperature is taken as the average of those measured during heating and cooling at $10 \mathrm{C} / \mathrm{min}$; the decreasing interval between the two temperatures as hardener level increases is due to faster diffusion at higher temperatures.

Commercial Alloys. The $\gamma^{\prime}$ solvus temperature of seven wrought alloys, including commercial disc alloys and wrought Pyromet 860 , measured during heating at $10 \mathrm{C} / \mathrm{min}$, are presented in Figure 12 . This plot of solvus temperature versus $\mathrm{Al}+\mathrm{Ti}$ content shows the progressive increase in solvus temperatures over the years, starting with the early-generation disc Alloy A-286, and proceeding to the higher-hardener alloys such as Inconel 718, Waspaloy, and René 95. An increase in solvus temperature of over $500 \mathrm{~F}$ is evident. (The

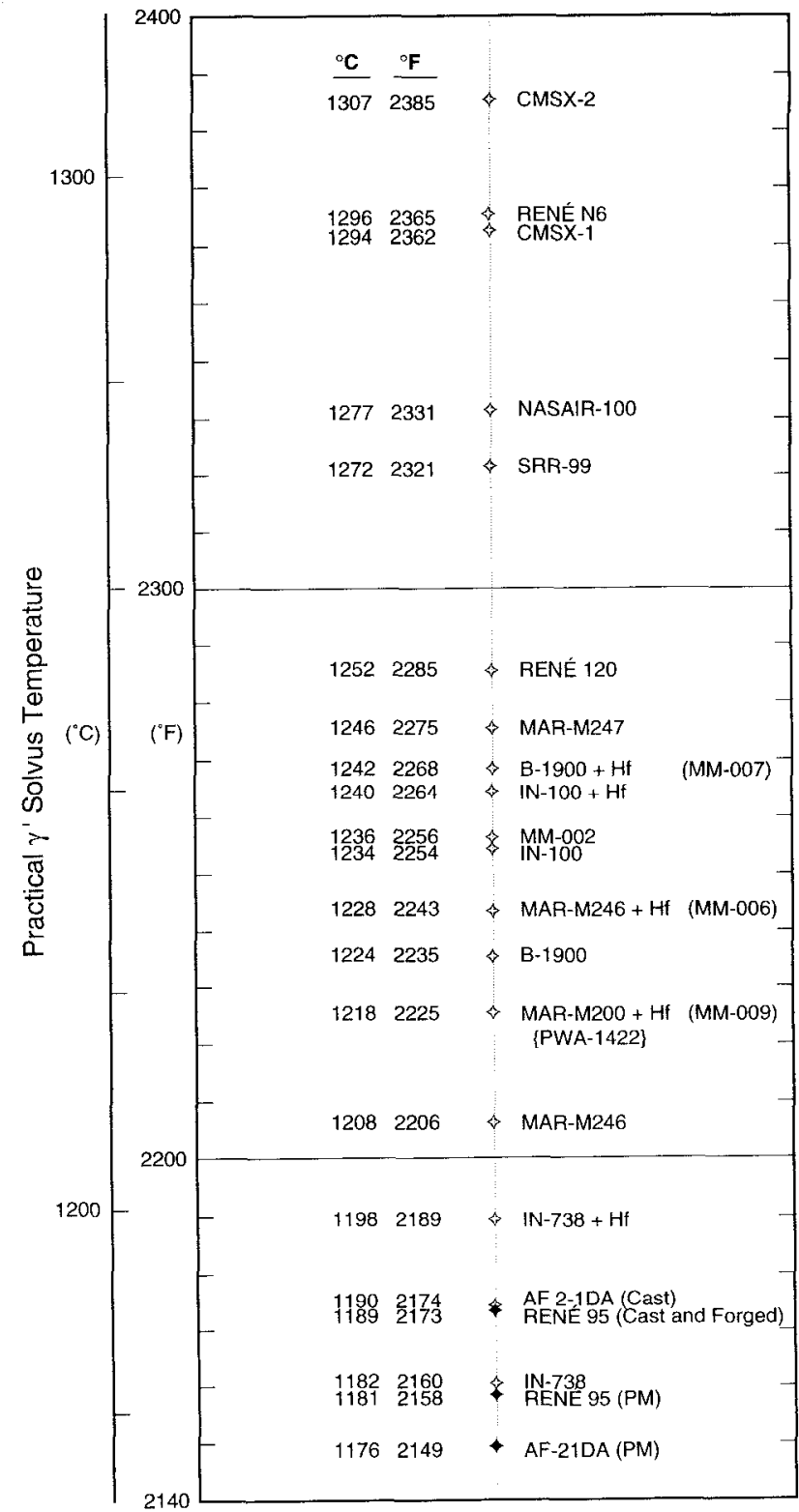

Figure 13. Practical $\gamma^{\prime}$ solvus temperatures for some well-known superalloys. All but three data points represent cast alloys, the wrought alloys being represented by solid symbols. The five alloys with the highest solvus temperatures are singlecrystal alloys. Note the effect of hafnium in raising the solvus temperatures of four alloys. Data were determined by DTA of solid-type specimens at a heating rate of $2 \mathrm{C} / \mathrm{min}$.

reason Inconel 718 and René 95 lie above the band is that their solvus temperatures are raised by high niobium content.)

The range of practical $\gamma^{\prime}$ solvus temperatures among 21 commercial or developmental alloys is shown in Figure 13. As described above, "practical" solvus temperatures are those obtained at a very slow heating rate, $2 \mathrm{C} / \mathrm{min}$, and closely represent the solvus temperature for a 2-hr heat treatment or soak prior to hot working. The alloys represented are primarily of the cast type, but the wrought alloys AF2-1DA (PM), René 95 (PM), and René 95 (cast and forged) are included. Because $\gamma^{\prime}$ is the primary high-temperature strengthener in nickel-base superalloys, and because the quantity of $\gamma^{\prime}$ tends to 
increase with increasing solvus temperature, the height of an alloy within Figure 13 serves as a general indicator of its high-temperature strength. Of special interest are the significant boosts in $\gamma^{\prime}$ solvus temperature of four of the alloys--IN-738, Mar-M246, B-1900, and IN-100-caused by the addition of $1.5-2 \%$ Hf. Alloys with $\gamma^{\prime}$ solvus temperatures above $1260 \mathrm{C}(2300 \mathrm{~F})$ are single-crystal alloys; mainly first-generation alloys are shown, but the state-of-the-art singlecrystal alloy René N6 is included.

Numerous superalloys containing hafnium have found their place in modern gas-turbine engines. The curves of Figure 14 illustrate a "fingerprint" of hafnium that shows up in the cooling thermogram of solid specimens after they have been heated to about $40 \mathrm{C}(70 \mathrm{~F})$ above the incipient-melting point. Shown are the cooling thermograms for IN-738 and 0.5, 1.0, and $1.5 \%$ Hf modifications thereof. At $1.0 \% \mathrm{Hf}$, and especially at $1.5 \% \mathrm{Hf}$, distinct sidepeaks are noted on the higher-temperature side of the $\gamma^{\prime}$ precipitation exotherm. These are caused by solidification of the $\gamma+\gamma^{\prime}$ eutectic constituent and by $\gamma^{\prime}$ precipitation that begins in the so-called "swirly" $\gamma^{\prime}$ regions before general precipitation of $\gamma^{\prime}$ begins in the rest of the matrix. This is attributed to enrichment of the matrix in the swirly zones by hafnium, a $\gamma^{\prime}$ former. Kotval et al. have shown that the boundaries of the "swirly" zones are enriched in boron (9). (The prominence of the hafnium sidepeak diminishes, owing to homogenization, as repeated DTA tests are made on the same specimen, not shown here). Because this phenomenon extends the $\gamma^{\prime}$ precipitation process over a wider temperature range, the peak height of the main $\gamma^{\prime}$ precipitation exotherm is progressively reduced by the hafnium additions.

The processing method can have a marked effect on the dissolution and precipitation of $\gamma^{\prime}$ in a given alloy. This is illustrated in Figure 15a, which compares heating and cooling thermograms for IN-738 in the cast and powder-metallurgy-consolidated conditions. During heating at $10 \mathrm{C} / \mathrm{min}$, the curve for the $\mathrm{PM}$ specimen rises much more sharply during the final stages of $\gamma^{\prime}$ dissolution than does that for the cast specimen. This reflects the greater uniformity of composition in the PM material because of the vastly finer dendritic structure in atomized powder particles than in an investment casting. Following

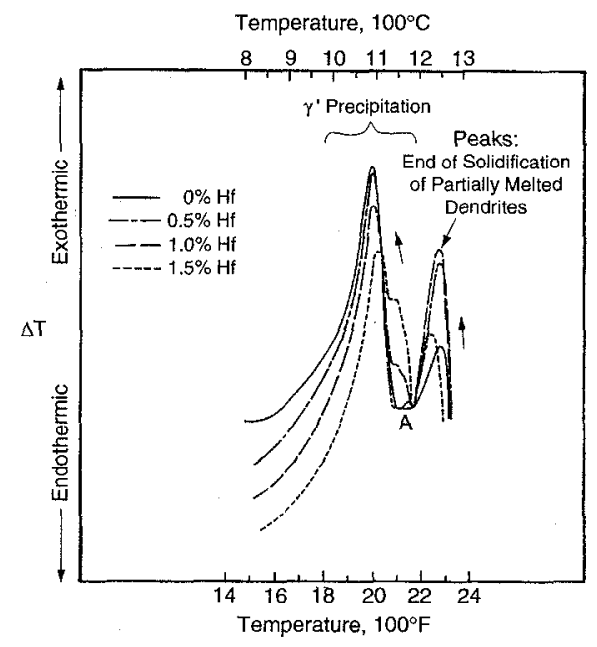

Figure 14. Effect of hafnium additions to $\mathbb{N}-738$ on the thermograms obtained during cooling after the solid-type specimens had been heated approximately $40 \mathrm{C}$ (70 F) above the incipient-melting point. Hafnium additions of $1 \%$ and $1.5 \%$ cause progressively larger sidepeaks at $\mathrm{A}$ on the high-temperature side of the main $\gamma^{\prime}$ precipitation exotherm, and hafnium additions progressively lower the height of the main exotherm, for reasons discussed in the text. Cooling rate: $\sim 25 \mathrm{C} / \mathrm{min}$. consolidation, the PM-processed $\mathrm{IN}-738$ is very homogeneous in chemical composition, while the casting is quite segregated. In a sense, the casting can be thought of as a composite of many alloys of closely spaced compositions. The thermogram for the metal of each composition would have a sharp rise to the $\gamma^{\prime}$ solvus point, similar to that for a PM sample. Because the curve for each of the aforementioned alloys would be displaced somewhat from the curves for the others, the combined effect of these displaced curves would be to spread out the rising portion of the thermogram near the $\gamma^{\prime}$ solvus. Thus, this portion is more than twice as wide for the cast specimen as for the PM specimen, $58 \mathrm{C}(105 \mathrm{~F})$ vs $28 \mathrm{C}(50 \mathrm{~F})$. (That this portion of the $\gamma^{\prime}$ dissolution endotherm for the PM specimen has a finite width should not be taken as an indication that the specimen retains significant segregation. Even a perfectly homogeneous specimen would have definite width at this stage, because of the curvature in the $\gamma^{\prime}$ solvus surface, as described previously.) Figure 15 a reveals a similar effect in the $\gamma^{\prime}$ precipitation exotherm of the cooling thermogram. The difference between the two specimens is lower, however, because of some homogenization that occurs in the cast specimen during its excursion above the incipient-melting point. The effect of homogenization may be seen more clearly in Figure $15 \mathrm{~b}$. This shows the progressive march to the right of the peak in the $\gamma^{\prime}$ precipitation exotherm as one cast specimen is tested during three successive runs. The flow of hardener into the lean areas at the skeleton of each dendrite raises its
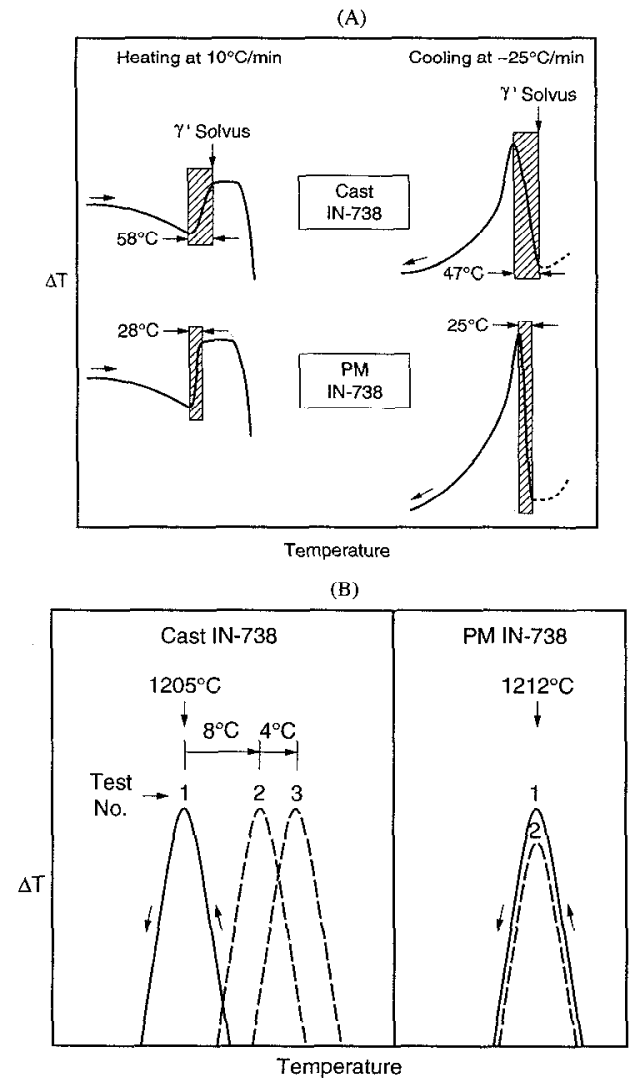

Figure 15. Effect of processing method on the thermograms of $\mathbb{N}-738$. (a) The temperature interval (crosshatched band) between the maximum thermal effect and the $\gamma^{\prime}$ solvus point is markedly lower, during both heating and cooling, for the PM specimen than for the cast specimen. (b) The peak of the $\gamma^{\prime}$ precipitation exotherm during cooling of the cast specimen shifts progressively to higher temperatures during successive DTA tests of the same specimen, because of incremental homogenization. No shift occurs for the PM specimen, because of its high homogeneity. 


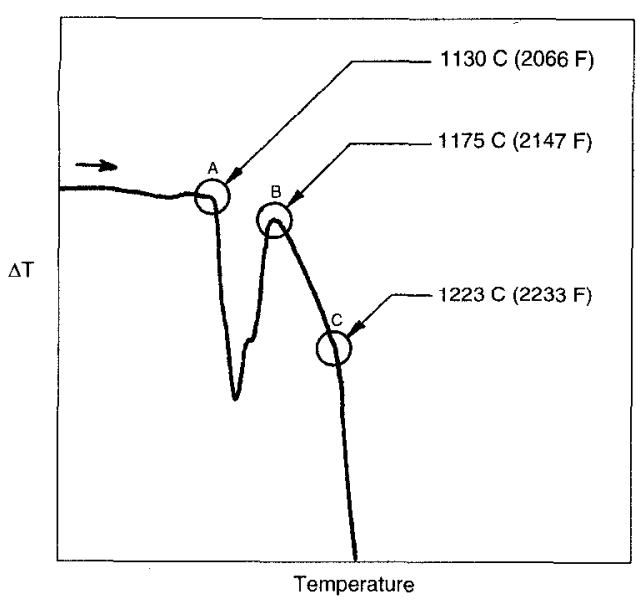

Figure 16. Distinct low-temperature melting reaction in Inconel-718, occurring at $1130 \mathrm{C}(2066 \mathrm{~F})$ during heating at $10 \mathrm{C} / \mathrm{min}$. The more-general melting reaction begins at a moderate rate at $1175 \mathrm{C}(2147 \mathrm{~F})$, and at a stronger rate at $1223 \mathrm{C}$ (2233 F).

$\gamma^{\prime}$ solvus and, hence, shifts the exotherm for the leanest region to higher temperatures. Two successive runs for the PM specimen, however, reveal no shift in the peak, indicating that the starting structure was quite homogeneous.

\section{Incipient Melting}

Knowledge of the temperature marking the very onset of melting is crucial to the control of superalloy processing and utilization. It has long been known that small amounts of liquid play havoc with the workability of superalloys; hot shortness thus causes severe cracking. This severe sensitivity to the presence of a small amount of liquid is undoubtedly aggravated by the "stiffness" and poor thermal conductivity associated with the high alloy content of superalloys. Lack of space does not permit a full exposition here of the limits posed on the workability of superalloys by incipient-melting. The most dramatic example of this effect, however, is presented by Inconel 718 , for which forging temperatures must be strictly limited to a maximum of $1120 \mathrm{C}(2050 \mathrm{~F})$. This is because the $5 \% \mathrm{Nb}$ content of this alloy causes some eutectic liquid to persist to very low temperatures, at which point Laves phase is formed. During heating at $10 \mathrm{C} / \mathrm{min}$, DTA reveals a distinct melting reaction in this region at $1130 \mathrm{C}(2066 \mathrm{~F})$, Figure 16 . The more general melting process begins at a moderate rate at $1175 \mathrm{C}(2147 \mathrm{~F})$ and at a stronger rate at $1223 \mathrm{C}(2233 \mathrm{~F})$.

The DTA method has been especially valuable in coping with the problem of unwanted partial melting during the solution treating of alloys possessing high $\gamma^{\prime}$ solvus temperatures. The difference in width of the so-called heat-treating "window" for solution heattreating among some familiar alloys is shown in Figure 17, for which the critical temperatures were determined during heating at a very slow rate, $2 \mathrm{C} / \mathrm{min}$, to obtain a realistic assessment of the $\gamma^{\prime}$ solvus and incipient-melting temperatures. Alloy $\mathrm{IN}-100$, with its very low incipient-melting point and high $\gamma^{\prime}$ solvus temperature, both caused by high hardener--especially titanium--content, has virtually no window, the width being just $7 \mathrm{C}(12 \mathrm{~F})$. Removing $3 \% \mathrm{Ti}$ from the IN-100 composition, while adding $10 \% \mathrm{~W}$ and replacing $1 \% \mathrm{~V}$ with $1.5 \% \mathrm{Ta}$, gives essentially the composition of Mar-M246. Inasmuch as tungsten raises both the $\gamma^{\prime}$ solvus temperature and incipient-melting point, the dominant effect is that of removing $3 \% \mathrm{Ti}$, which strongly lowers the solvus temperature

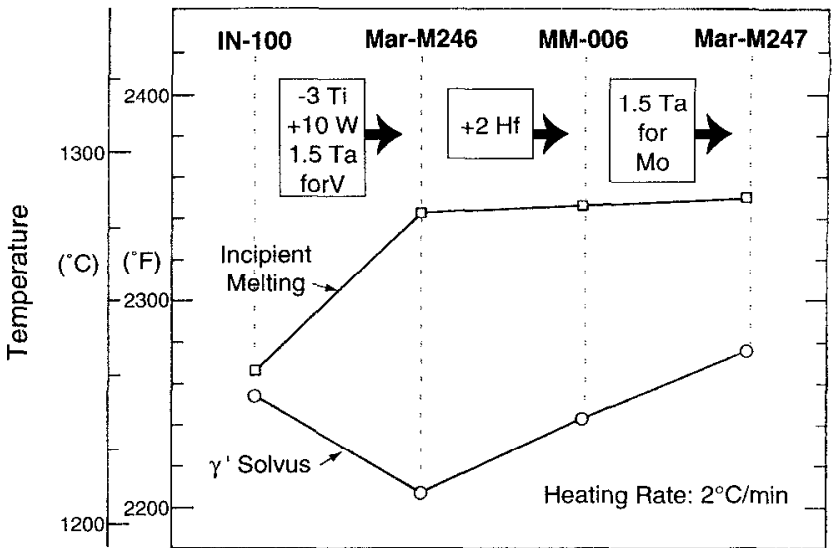

Figure 17. Effects of main compositional differences between well-known alloys on practical $\gamma^{\prime}$ solvus temperature and on incipient-melting temperature during heating at $2 \mathrm{C} / \mathrm{min}$, and thus on the width of the solution-heat-treating "window." The window is changed most sharply by titanium.

and strongly raises the incipient-melting point. This movement of the two critical temperatures in opposite directions thereby leads to a very wide window--76 C (136 F). Adding about $2 \%$ Hf $(1.9 \%$ in the present study) narrows the window appreciably [to $57 \mathrm{C}(103 \mathrm{~F})$ ] for the resulting MM-006 alloy, mainly because hafnium raises the solvus temperature significantly. The further substitution of $1.5 \% \mathrm{Hf}$ for about an equal amount of molybdenum (and slight reduction in hafnium content) leads to the Mar-M247 composition. Because the tantalum addition raises the solvus temperature considerably more than it does the incipient-melting temperature, a significantly narrower window results-- $43 \mathrm{C}(74 \mathrm{~F})$.

Control of the heat-treating window is most crucial for singlecrystal superalloys, a class of alloys for which the maximum amount of hardener has been "packed in" to maximize high-temperature strength. Strong melting-point depressants have been replaced, in part, by strengtheners with a milder effect, or that even tend to raise the incipient-melting point, thus permitting a raising of the solvus temperature and/or a widening of the window.

Figure 18 presents DTA results for the state-of-the-art production turbine-blade Alloy René N6 (Ni-12.5Co-4.2Cr-1.4Mo-6W-5.9Re7.2Ta-5.75Al-0.15Hf-0.01Y) (10) and three other (experimental) single-crystal alloys, all fully heat treated, supplied by GE Aircraft Engines. Though their compositions are proprietary, all experimental alloys are identical in composition, except for having different levels of cobalt, namely, 5, 12.5, and 20\%. The critical temperatures obtained by DTA at a heating rate of $4 \mathrm{C} / \mathrm{min}$ are shown in Figure 18. Besides prescnting the $\gamma^{\prime}$ solvus temperature and incipientmelting temperature, the graph shows the temperature at which the maximum thermal effect (minimum in the main endotherm during heating) occurs. This represents the temperature at which the maximum rate of $\gamma^{\prime}$ dissolution occurs for each alloy. Also shown, connected to the heating data points by dashed lines, are the temperatures of the corresponding $\gamma^{\prime}$ reactions during natural cooling at about $25 \mathrm{C} / \mathrm{min}$, i.e., the start of $\gamma^{\prime}$ precipitation, and the maximum thermal effect, representing the maximum rate of $\gamma^{\prime}$ formation (peak of the main exotherm). The following observations are noteworthy:

(1) René N6 has rather high $\gamma^{\prime}$ solvus and incipient-melting temperatures, $1299 \mathrm{C}(2370 \mathrm{~F})$ and $1340 \mathrm{C}(2444 \mathrm{~F})$, respectively, the difference giving it an adequately wide heat-treating window, $41 \mathrm{C}(74 \mathrm{~F})$. Alloy X-1 has exceptionally high $\gamma^{\prime}$ solvus and 
incipient-melting temperatures, $1340 \mathrm{C}(2444 \mathrm{~F})$ and $1372 \mathrm{C}$ (2502 F), respectively, and a $32 \mathrm{C}(58 \mathrm{~F})$ window.

(2) Among the three experimental alloys, increasing the cobalt content lowers the $\gamma^{\prime}$ solvus temperature sharply and the incipientmelting temperature mildly, thereby widening the window to $46 \mathrm{C}$ $(82 \mathrm{~F})$ at $12.5 \% \mathrm{Co}$ and to $68 \mathrm{C}(122 \mathrm{~F})$ at $20 \% \mathrm{Co}$, intervals that are greater than necessary for ease of solution heat treating. This raises the possibility of increasing the hardener content and strength of these two alloys.

(3) The width of the interval between the temperature of the maximum thermal effect and the $\gamma^{\prime}$ solvus temperature during heating provides a useful qualitative indicator of the degree of homogenization in the casting. This is seen in the following comparison of the temperature intervals during beating:

$\begin{array}{ccccc}\text { René N6 } & \underline{X}-1 & \underline{X}-2 & X-3 & X-1,2,3 \mathrm{Avg} \\ 17 \mathrm{C} & 23 \mathrm{C} & 22 \mathrm{C} & 20 \mathrm{C} & 22 \mathrm{C} \\ (30 \mathrm{~F}) & (42 \mathrm{~F}) & (39 \mathrm{~F}) & (36 \mathrm{~F}) & (39 \mathrm{~F})\end{array}$

The interval for René N6 is considered to be close to the minimum possible for a fully homogenized alloy, the minimum reflecting the curvature in the $\gamma^{\prime}$ solvus surface, as discussed previously. The interval for each of the experimental alloys is significantly wider, the average difference being $5 \mathrm{C}(9 \mathrm{~F})$. Similar differences are indicated by the cooling data points of Figure 19. This suggests more segregation in the experimental alloys than in René N6. Such a difference was clearly confirmed metallographically, as illustrated in Figure 19, and reflects the longer solution heat treatment that had been used for René N6 than for the experimental alloys. This effect is similar to that described earlier for the difference, between cast (segregated) and powder metallurgy (nearly homogeneous) IN-738, with regard to the width of this temperature interval, Figure 15 . The foregoing suggests that careful measurement of this interval can be used to monitor the degree or progress of homogenization in nickelbase superalloys.

The solution-heat-treating windows of 24 single-crystal alloys evaluated by the author are presented in Figure 20. Represented are five commercial alloys, including the René N6 described above, and 19 proprietary, experimental, or developmental alloys from different sources, including the experimental alloys $X-1, X-2$, and $X-3$ described above. The bottom of each bar represents the alloy's practical $\gamma^{\prime}$ solvus temperature, and the top represents the incipientmelting temperature. The bars of Figure 20 reveal quite a large range of $\gamma^{\prime}$ solvus temperatures, especially because of the low solvus temperature of $\mathrm{MM}-002$. The widths of the windows vary from about zero to $71 \mathrm{C}(127 \mathrm{~F})$. Thus some alloys would be impossible to solution heat treat without incurring incipient melting, while other alloys have excessively wide windows-larger than needed for ease of heat treating-thus indicating the possibility of raising hardener content for the sike of improving high-temperature strength.

\section{Problem-Solving}

In the following are given a few examples of how DTA of solid specimens has been used to solve practical problems in the casting of superalloys. The first one has to do with a serious and longstanding hot-tearing problem in the casting of medium-sized Alloy $713 \mathrm{C}$ integral turbocharger wheels. A DTA specimen taken from a cracked wheel containing $0.15 \% \mathrm{Zr}$ revealed the presence of a very-low-melting (about $1100 \mathrm{C}|2000 \mathrm{~F}|$ ) liquid in both the heating and cooling thermograms, as encircled in Figure 21a. Because pockets of high-zirconium constituent were detected near

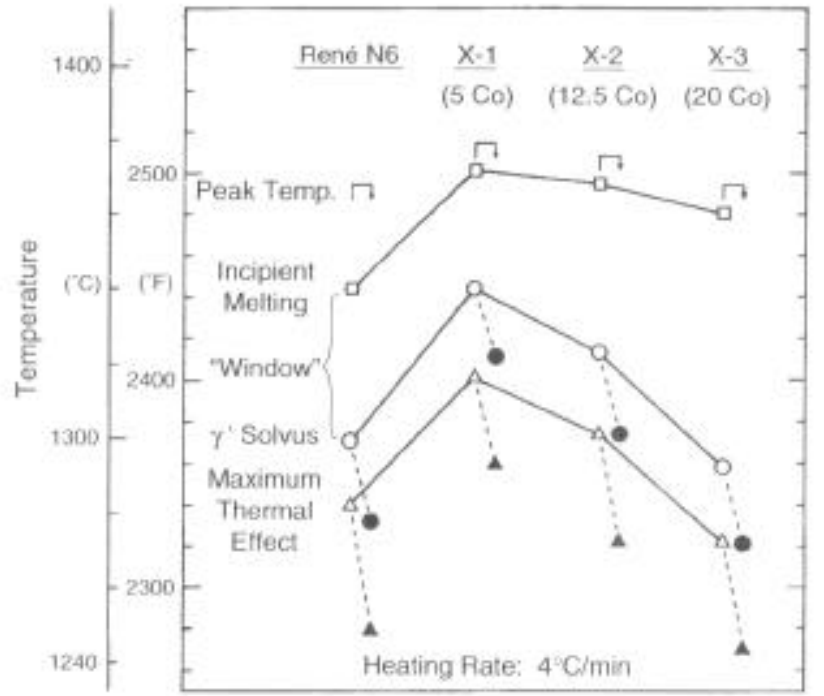

Figure 18. Critical temperatures of the single-crystal Alloy René N6 and three experimental alloys, as dotermined by DTA during heating at $4 \mathrm{C} / \mathrm{min}$. The window is widened markedly by cobalt. Critical temperatures obtained during natural cooling $(-25 \mathrm{C} / \mathrm{min})$ are denoted by solid symbols and are connected to their corresponding temperatures obtained during heating by dashed lines.

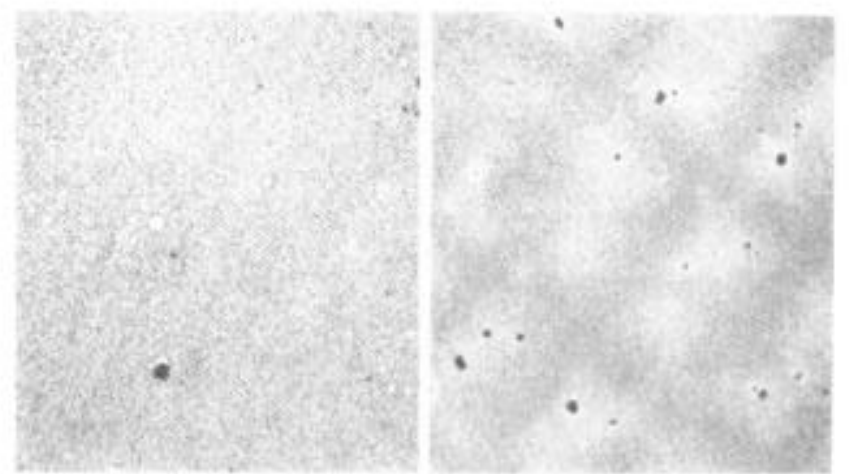

Figure 19. Microseructures of Rent N6 (lefi) and Experimental Alloy X-3 (right) in the beat-treated condition. The former alloy exhilvits neglighle segregation, while the latter is distinctly cored. The existence of this differmoe was indicated by DTA. $75 \mathrm{X}$.

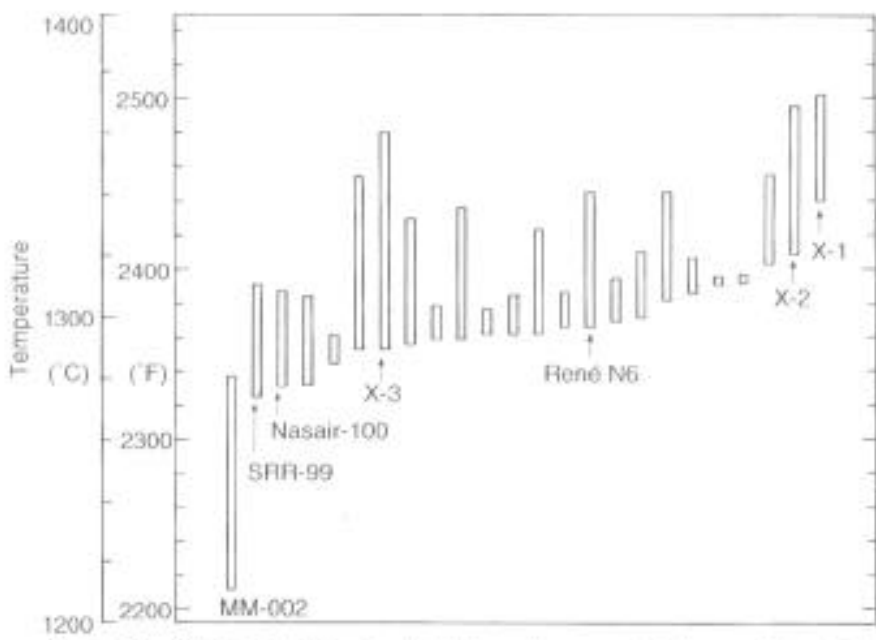

Figure 20, Solution-heat-treating "windows," repsesented by open bars, for 24 experimental and first-generation single-crystal alloys. Stute-of-the-art alloy René N6 also is shown. Alloys are arranged in order of increasing practical $\gamma^{\prime}$ solvus temperatures: 
the crack, test castings made from alloys doped with various levels of zirconium were examined for hot tears. The results show a striking correlation between the incidence of hot tears and zirconium content:
$0.09 \% \mathrm{Zr}$
$0.15 \% \mathrm{Zr}$
$0.19 \% \mathrm{Zr}$
$0 \%$ hot tears ( 0 of 12$)$
$50 \%$ hot tears (6 of 12$)$
$100 \%$ hot tears (12 of 12$)$

The powerful effect of zirconium in promoting the very-low-melting liquid is seen in the thermograms of Figure $21 \mathrm{~b}$, representing unusually high $(0.34 \%)$ zirconium content in hafnium-modified B-1900; very prominent low-melting reactions (encircled) are evident during heating and cooling. Subsequent control of the zirconium content in the Alloy $713 \mathrm{C}$ remelt ingot eliminated the costly hot tearing of the wheels.

Microporosity in castings of $\mathrm{IN}-100$ led to a comparison of good and bad castings by DTA, Figure 22. Perturbations (encircled in Figure $22 \mathrm{~b}$ ) in the thermograms were noted for the most porosityprone castings. These inflections indicate the presence of $\gamma+\gamma^{\prime}$ eutectic. The development of this constituent, and the porosity itself, could have been influenced by a higher-than-normal concentration of nitrogen detected in the porous castings.

A somewhat similar problem of microporosity was observed in castings of MM-002. Both the heating and cooling portions of the thermograms for porous castings, obtained during heating at $2 \mathrm{C} / \mathrm{min}$ followed by natural cooling, possessed strong indications of the inflections associated with the $\gamma+\gamma^{\prime}$ eutectic constituent. Such inflections are marked $B$ and $C$ in Figure 23. It was noted that the reaction was so strong that it even continued above the incipientmelting point for some castings (not illustrated here). As an indication of the intensity of the reaction, the ratio of the height of the eutectic $\gamma^{\prime}$ inflections ( $B$ and $C$ ) to the height of the main endotherm/exotherm for the dissolution/precipitation, respectively, of matrix $\gamma^{\prime}$ marked $\mathrm{A}$ and $\mathrm{D}$, respectively, are as follows:

$\begin{array}{lcc}\frac{\text { Ratio }}{\text { B/A, Heating }} & \text { Sound Casting } & \text { Porous Casting } \\ \text { C/D, Cooling C/D } & 0.49 & 3.27 \\ 0.15 & 0.24\end{array}$

Ratios are smaller during cooling, partly because of partial absorption of the eutectic $\gamma^{\prime}$ by the matrix during the hottest part of the DTA test. Nevertheless, it is seen that higher ratios are associated with, and apparently indicative of, the tendency toward excessive microporosity.

\section{Summary}

Differential thermal analysis (DTA) performed on specimens of more than 200 model, experimental, developmental, and commercial nickel-base superalloys, using large specimens with internally positioned thermocouples, has revealed much useful information. about the critical phase changes and microstructures governing the processing and performance of this important class of alloys.

Studies of eight Ni-15Cr-10Co-5Mo-C-Al-Ti-Ta model alloys during melting and solidification show that the carbide eutectic reaction occurs at very low temperatures in the absence of a strong carbide former, and that carbide formation occurs progressively earlier in the solidification process as the quantities of strong carbide-forming reactants increase, an alloy with $0.16 \mathrm{C}-3 \mathrm{Al}-3 \mathrm{Ti}-6 \mathrm{Ta}$ forming carbides well before (75 $\mathrm{C}[135 \mathrm{~F}]$ above) the start of metallic dendrite formation. The specific effects (per $1 \mathrm{wt}$ pct) of aluminum, titanium, and tantalum on liquidus temperature during solidification are

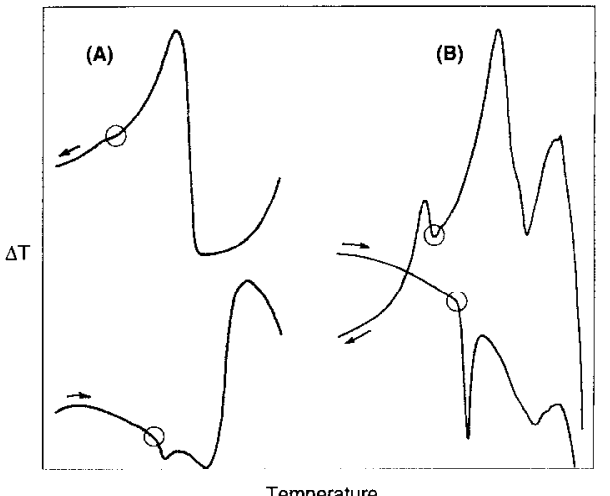

Temperature

Figure 21. Thermograms illustrating the use of DTA to identify the cause of hot tearing in Alloy $713 \mathrm{C}$ turbocharger wheel castings. (a) Small irflections A and $B$ in the heating and cooling thermograms, respectively, for only the cracked castings suggested that low-melting liquid caused by zirconium was responsible. (b) The powerful effect of zirconium in promoting such low-melting liquid is seen in these thermograms of modified B-1900 containing $1.35 \% \mathrm{Hf}$ and $0.34 \% \mathrm{Zr}$, which have very prominent indications of low-melting liquid (encircled).

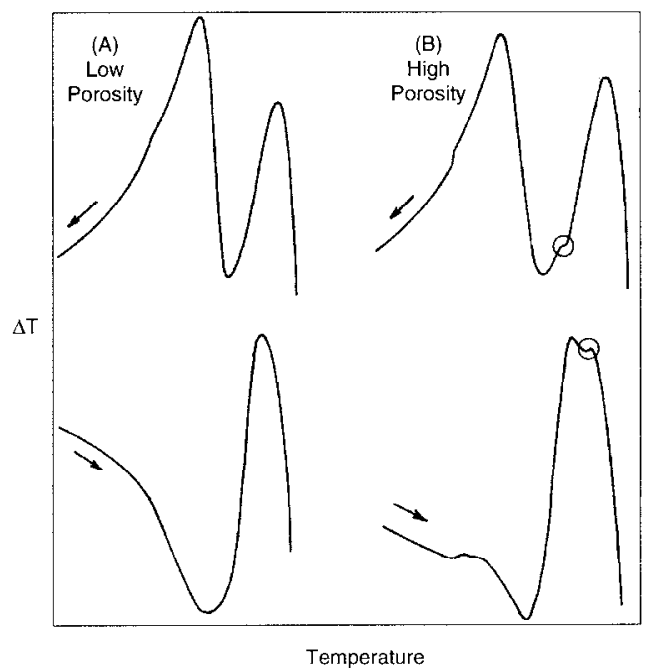

Figure 22. Thermograms for IN-100 castings having low and high amounts of porosity. The encircled inflections telated to the $\gamma+\gamma^{\prime}$ eutectic const ituent were found only in castings of high porosity.

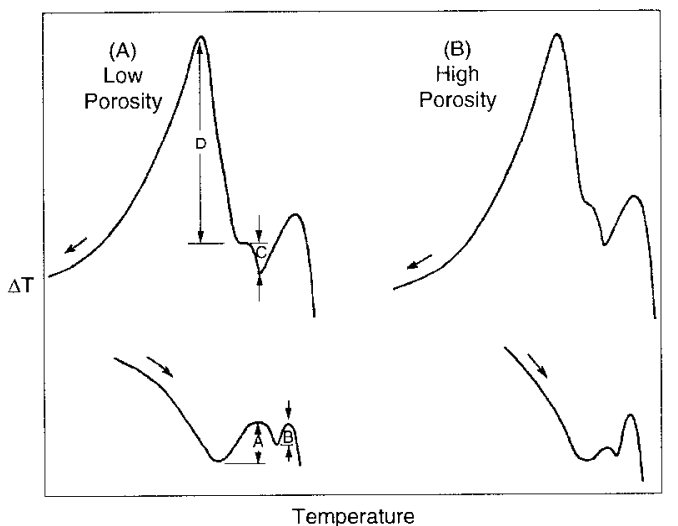

Figure 23. Thermograms for MM-002 castings having low and high amounts of porosity. Both castings had strong DTA indications of the $\gamma+\gamma^{\prime}$ eutectic reaction, but porosity was worse in those castings with higher $\mathrm{B} / \mathrm{A}$ and $\mathrm{C} / \mathrm{D}$ ratios, denoting more of the $\gamma+\gamma^{\prime}$ constiment. 
presented. Solidification ranges, and alloying effects thereon, of some well-known commercial alloys are given.

Measurements of $\gamma^{\prime}$ solvus temperature (for matrix precipitate and for eutectic $\gamma^{\prime}$ ) and of incipient-melting temperature are best performed on large solid specimens with internal thermocouple contact, giving direct and precise indications of these critical temperatures and providing other useful information as well. Features of thermograms were identified by calibration studies of thin bars of four cast alloys heated at $10 \mathrm{C} / \mathrm{min}$ in a thermal gradient furnace and quenched, and of 35 small disc specimens of various cast alloys quenched from the DTA furnace at temperatures corresponding to various points on heating and especially on cooling thermograms. Indicated $\gamma^{\prime}$ solvus temperatures decrease moderately as heating rate decreases; values determined at $2 \mathrm{C} / \mathrm{min}$ agree closely with those for practical 2-hour annealing and soaking treatments. Guided by the above results, the effects of alloying elements and of processing on $\gamma^{\prime}$ solvus and/or incipient-melting temperatures of alloys are presented. Of special interest is the unique ability of DTA to directly and precisely reveal the width of the temperature interval, or "window," for the solution heat treating of single-crystal alloys; windows ranging from essentially zero to $71 \mathrm{C}(127 \mathrm{~F})$ in width are reported.

Examples are presented of using DTA to solve costly problems of hot tearing and excessive microporosity in castings.

In the 28 years since $\gamma^{\prime}$ solvus temperatures were first measured by DTA, this technique has established itself widely in the superalloy industry, owing to its great utility in monitoring the critical phase changes that are important in the metallurgical development and process-control of superalloys. The value of DTA in the metallurgy of superalloys already is considered by the author to be at least as great as that of dilatometry in the metallurgy of transformable and hardenable steels. Hopefully, the results described herein may further advance the usefulness of DTA in the metallurgy of superalloys.

\section{Acknowledgcments}

The author is deeply indebted to: W.T. Loomis, whose doctoral research created the opportunity for discovering that $\gamma^{\prime}$ solvus temperatures could be measured directly by DTA; G.A. Timmons, D.V. Doane, and the late M. Semchyshen, for maintaining financial support for DTA studies; W.P. Danesi, R.G. Dunn, and C.C. Clark, for providing many interesting sample sets of superalloys for DTA analysis; W.S. Walston, for supplying single-crystal alloys; W.C. Hagel, W.J. Boesch, D.R. Muzyka, C.R. Whitney, J.A. Petrusha, J.H. Wood. L.S. Taylor, P.D. Spilling, G.L. Erickson, J. Domingue, R. Egbert, and the late G.E. Marshall, for enlightening discussions; R.C. Binns, D.E. Schumacher, E.K. Ohriner, M.C. LaPine, R.R. Lannin, and R.W. McConnell, for assistance with DTA experiments; and D.J. Kruzich, K.S. Smalinskas, D.J. Pipe, and M.S. Snell for assistance in manuscript preparation. The author is most indebted to, and dedicates this paper to his wife Mary, a "DTA widow" on too many nights and weekends, for her considerable patience and steadfast support throughout the very long research stage and the preparation of the manuscript, adding immeasurably to the success of this endeavor.

\section{References}

1. H. LeChateliér, "The Action of Heat on Clays," Compt. rend. 104 (1887), pp. 1443-46.

2. W.C. Roberts-Austen, "Fifth Report to the Alloys Research Committee," Proc. Inst. Mech. Engrs. (London) 1 (1899), pp. 35-102.

3. D.L. Sponseller, W.G. Scholz, and D.F. Rundle, "Development of Low-Alloy Ductile Irons for Service at 1200-1500 F," AFS Transactions 76 (1968), pp. 353-68.

4. W.T. Loomis, J.W. Freeman, and D.L. Sponseller, "The Influence of Molybdenum on the $\gamma^{\prime}$ Phase in Expcrimental Nickel-Base Superalloys," Metallurgical Transactions 3 (1972), pp. 989-1000.

5. D.L. Sponseller, "Differential Thermal Analysis of Superalloys," presented at the session Physical Metallurgy of Superalloys," ASM/AIME Materials Science Symposium, Oct 21-24, 1974, Detroit, MI.

6. D.L. Sponseller, "Use of Differential Thermal Analysis in the Melting, Casting, and Heat Treating of Superalloys," presented at the 1975 Vacuum Metallurgy Conference, June 23-25, 1975, Columbus, $\mathrm{OH}$.

7. Y. Zhu, S. Zhang, T. Zhang, J. Zhang, Z. Hu, X. Xie, and C. Shi, "A New Way to Improve the Superalloys," Superalloys 1992, pp. 145-154.

8. G.E. Maurer, J. Domingue, and W.J. Boesch, "Superalloy Design with Differential Thermal Analysis," Proceedings of the 27th Annual Meeting of the Investment Casting Institute (1979), Rosemont, IL, pp. 16:01-16:23.

9. P.S. Kotval, J.D. Venables, and R.W. Calder, "The Role of Hafnium in Modifying the Microstructure of Cast Nickel-Base Superalloys," Metallurgical Transactions 3 (1972), pp. 453-458.

10. W.S. Walston, E.W. Ross, K.S. O'Hara, T.M. Pollock, and W.H. Murphy, U.S. Patent 5,455,120, "Nickel-Base Superalloy and Article with High-Temperature Strength and Improved Stability," René N6, 1995. 